Inteligência de Governança para apoio à Tomada de Decisão

\author{
Intelligence in Governance \\ for Support in Decision-Making
}

\section{Luiz Odorico Monteiro de Andrade ${ }^{1}$}

Agradeço a oportunidade de participar dessa discussão que envolve tema tão relevante para o SUS. Oswaldo Tanaka nos brinda com um texto instigante e oportuno, face aos desafios apresentados para o estabelecimento de sistemas universais de saúde, principalmente no que diz respeito aos três domínios analisados: gestão, avaliação e tomada de decisão.

O artigo chega em momento muito especial. Primeiro por se inserir num processo de maturação da avaliação em saúde no Brasil. A rica produção epistêmica, bem referenciada por Tanaka, de autores brasileiros e estrangeiros, em parcerias ou não ${ }^{1-7}$. Segundo, o artigo sucede a recente contribuição sobre a institucionalização da avaliação $0^{8,9} \mathrm{e}$, terceiro, ele "presencia o nascimento" do Índice de Desempenho do Sistema Único de Saúde - IDSUS, pactuado na Comissão Intergestores Tripartite ${ }^{10}$, de 15 de dezembro de 2011.

O IDSUS, elaborado pelo Departamento de Monitoramento e Avaliação do SUS (DEMAS), da Secretária Executiva do Ministério da Saúde, se propõe a avaliar o desempenho do SUS a partir do acesso e da qualidade das ações e serviços de saúde. Para sua formulação considerou-se a estrutura teórico-metodológia do Projeto de Avaliação de Desempenho do Sistema de Saúde Brasileiro (PROADESS $)^{11-13}$. A análise de desempenho será feita a partir do cruzamento de indicadores simples e compostos e aplicada aos entes federativos: municípios (organizados ou não em regiões de saúde), estados e União.

Kickbusch e Payne ${ }^{13}$ enfatizam que o processo de urbanização e industrialização ocorrido no século XX teve como um de seus legados colocar a saúde no cerne da modernidade e do desenvolvimento econômico-social, contribuindo com a modelagem, natureza e estruturação do Estado-nação e suas instituições sociais. Esse fato, aliado à disputa que se trava, ainda nos dias de hoje na sociedade ocidental, sobre a saúde ser um direito de cidadania e um dever do Estado ou ser regida pelas leis de mercado fez com que a sua gestão gravitasse sistematicamente em torno de crises que rondam o setor todo o tempo. Nesse contexto o artigo em análise se apresenta como uma grande contribuição para a Avaliação da Gestão de Serviços de Saúde - AGSS.
Nesse passo gostaria de trazer à tona o conceito de governança por considerá-lo mais abrangente do que o de governabilidade.

O conceito de governabilidade, fortemente desenvolvido na área do Planejamento estratégico por Matus $^{14}$, foi também incorporado ao campo das ciências sociais e do jornalismo político a partir da década de 70 . Na opinião de Martins ${ }^{15}$ a governabilidade é apenas um índice por constituir uma variável que em dado momento, retrata as relações entre governantes e governados. Santos ${ }^{16}$, ao discutir esses dois conceitos, esclarece que a primeira geração de análise sobre governabilidade foi originada dos trabalhos de Samuel Huntington ${ }^{17}$ - produzidos no período de 1965 a 1975, entre os quais se destaca Political order in changing societies ${ }^{18}$, publicado pela Yale University. Este trabalho interpreta a crise de governabilidade como fruto dos excessos da participação e sobrecarga de demandas.

O funcionamento adequado dos sistemas políticos depende do equilíbrio entre as instituições de input agregadoras de interesses, sobretudo os partidos, e as instituições governamentais de output, que regulam e implementam as políticas públicas. No contexto das democracias consolidadas, quando surgiu a onda de participação social, seguiu-se, em resposta, um aumento da atividade governamental, acompanhado de sobrecarga no governo com falência de outputs e deslegitimação da autoridade, com subsequente enfraquecimento das instituições políticas. Para Pasquino ${ }^{18}$ a governabilidade e a não governabilidade não são fatos completos, mas processos em curso compostos de relações complexas entre componentes de um sistema político.

A governança é um fenômeno mais amplo do que governabilidade. Ela abrange as instituições governamentais, mas implica também mecanismos informais de caráter não governamental, os quais fazem com que as pessoas e as organizações dentro de sua área de atuação tenham uma conduta determinada, satisfaçam suas necessidade e respondam às suas demandas. Como ressaltam Rosenau e Czempiel ${ }^{19}$, governança não é o mesmo que governabilidade. Enquanto governabilidade sugere atividades sustentadas por uma autoridade formal, pelo poder de autoridade que garante a implementação das políticas formalmente instituídas, governança refere-se a atividades apoiadas em objetivos comuns, que podem ou não derivar de responsabilidades legais e formalmente prescritas e não de-

\footnotetext{
${ }^{1}$ Faculdade de Medicina - Campus Sobral, Universidade
} Federal do Ceará. odorico0811@gmail.com 
pendem, necessariamente, do poder de autoridade para que sejam aceitas e vençam resistências.

Para Denis et al. ${ }^{20}$ a governança na administração pública é multidimensional e se refere à conduta de ações coletivas de uma posição de autoridade . A "ação coletiva" está associada a organizações formais como hospitais, centros de saúde etc. "Posição de autoridade" se refere à legitimidade formal ou legal dada a um corpo para o controle e capacidade de adaptação de uma organização ou sistema. Este conceito ajusta-se melhor ao processo que vivenciamos hoje na implementação do Sistema Único de Saúde no Brasil pelo seu caráter de rede interfederativa ${ }^{21}$ a qual implica em ações compartilhadas de entes federativos.

Em muitos cenários, um órgão como o Ministério da Saúde, por exemplo, vem buscando mais governança do que governabilidade mediante os processos de decisão colegiada do SUS expressadas nas comissões intergestores tri e bipartite. Associa-se a isso a permanente necessidade de negociação com o controle social pelas conferências e conselhos de saúde. Entretanto, ainda que o Ministério da Saúde vise mais a governança atuando de maneira colegiada, as pactuações nem sempre se concretizam ante a falta de instrumentos jurídicos formais com força vinculante entre as esferas governamentais. Nesse sentido, entendemos que no âmbito do Sistema Único de Saúde há baixa governança, devendo-se adotar instrumentos jurídicos, conforme previsto no Decreto 7.508, de 2011 (contrato organizativo da ação pública), com a finalidade de aprimorá-la. Assim, deve-se primar pela diminuição de ações que visem mais a hierarquia administrativa do que as relações de cooperação e colaboração.

Smith $^{22}$, em um editorial do BMJ, enfatiza que estamos vivenciando uma transição nos sistemas de saúde ao sairmos do modelo da "Era Industrial" para o modelo da "Era da Informação". Para o autor, o modelo da era industrial, que marcou fortemente os sistemas ocidentais, é piramidal tendo na sua base a atenção primária, seguida pela secundária e no ápice a terciária. É um modelo fortemente centrado no profissional e nos gestores como autoridades enquanto no modelo da era da informação esta pirâmide encontra-se invertida e passa a ter em sua base o autocuidado, seguida pela família e amigo, e depois, pelas redes sociais. Os profissionais vêem em seguida como parceiros, facilitadores e como autoridade.

Esse enfoque reforça a proposta do artigo de Oswaldo Tanaka, corroborada por Denis ${ }^{9}$ de que deve-se privilegiar a perspectiva participativa da avaliação a qual nos obriga a construir cenários entre os "avaliadores" e os tomadores de decisão. Dubois et al. ${ }^{7}$, dialogando com Guba e Lincoln ${ }^{23}$, denominam de "geração da avaliação caracterizada pela negociação" o momento atual. Neste sentido, propomos aqui cinco os cenários para a tomada de decisão: 1) o cidadão-usuário; 2) a família; 3) a sociedade; 4) técnicos e administradores; 5) gestores. Em se tratando de tomada de decisão uma categoria central desse processo é o poder. O Professor Mário Testa ${ }^{24}$ nos lega uma importante contribuição quanto a isso ao definir que o "poder em saúde" se dá nos espaços técnicos, administrativos e políticos.

Por sua vez, Denis ${ }^{9}$ propõe que modelos ideais de avaliação devem abrigar as três dimensões: 1 ) Avaliação orientada para metas e objetivos; 2) Avaliação baseada na teoria; 3) Avaliação participativa.

Nesse passo, levando em consideração o exposto, é importante trazer para o debate o desenvolvimento de um trabalho recente, fruto de pesquisas de fronteira, realizados por médicos da área da saúde coletiva, Andrade e Santos ${ }^{25}$, e Oliveira et al. ${ }^{26}$, engenheiro da área de tecnologia da informação e comunicação (TIC), denominado LARIISA.

No contexto de tecnologias de alta sensibilidade ("context-aware technology" ou "Sensibilidade ao Contexto" contempla qualquer informação que possa ser usada para caracterizar a situação de entidades - seja ela uma pessoa, lugar ou objeto que seja considerada relevante para interações entre usuários e aplicações ${ }^{27}$ e de modelagem baseada em ontologias (na Ciência da Computação e na Ciência da Informação uma Ontologia é um modelo de dados que representa um conjunto de conceitos dentro de um domínio e os relacionamentos entre estes. Uma ontologia é utilizada para realizar inferência sobre os objetos do domínio ${ }^{28}$ que informam e conformam o framework LARIISA esse projeto poderá ter grande importância para a tomada de decisão na saúde. Esse projeto objetiva a pesquisa e o desenvolvimento de uma plataforma capaz de fornecer inteligências de governança para apoio à tomada de decisão na gestão de sistema de saúde a partir de informações coletadas/enviadas das residências (indivíduo e família) para, em seguida, serem tratadas por técnicos, administradores e gestores.

Esta modelagem foi concebida a partir de cinco domínios de inteligência. 1) Inteligência de Gestão do Conhecimento: relacionada a processos que possam produzir, construir, sistematizar e transferir o conhecimento gerado mediante processos formais de pesquisa, processos empíricos e demais formas que permitam a geração de novos conhecimentos e seu aperfeiçoamento; 2) Inteligência Normativa: 
relacionada a participação dos agentes públicos ou dos gestores da saúde na elaboração das leis, visando a geração de normas que possam, de fato, dar consistência, concretude e segurança jurídica ao sistema; 3) Inteligência Clínica-Epidemiológica: visa garantir ao gestor o conhecimento dos processos saúde-doença, a partir do conceito de que saúde tem como fatores determinantes e condicionantes o biológico, o social, o econômico, o genético, o estilo de vida e a influência dos serviços de saúde organizados em redes, bem como um conjunto de rotinas clinicas através de seus protocolos; 4) Inteligência Administrativa: relacionada aos processos de gestão administrativa; 5) Inteligência de Gestão Compartilhada: relacionada à participação social e à gestão compartilhada dos entes federativos.

O framework LARIISA evoluiu na direção de uma prova de conceito a partir da modelagem e implementação de um protótipo tendo como cenário o domínio clínico-epidemiológico (técnicos e administradores). O protótipo ${ }^{29-31}$ está orientado para agravos de dengue, sendo capaz de perceber o status de uma emergência epidemiológica e adaptar-se ao contexto (local e global). Como resultado, ele fornece mapas epidemiológicos para a tomada de decisão dos gestores (governo) e afeta dinamicamente a agenda dos agentes de saúde (no âmbito técnico e administrativo) em função de seu contexto (perfil profissional, localização, disponibilidade, etc.).

Os pontos de convergência entre a modelagem LARIISA e o artigo de Tanaka demonstra que estamos no caminho certo no desenvolvimento desse projeto para tomada de decisão.

Vejamos alguns destes pontos: sensibilidade a contexto: A ideia de contexto, conceito chave na arquitetura LARIISA, tem presença forte na proposta do artigo em debate quando afirma: $O$ conhecimento do contexto da avaliação é essencial para estabelecer o seu objetivo...; Informação em tempo real: O fornecimento de informação em tempo hábil para o gestor é imprescindivel para a melhoria qualitativa das decisões; Representação do Conhecimento: A avaliação pode ser referida como um conhecimento produzido no campo teórico-metodológico aplicável a um objeto quando há a necessidade de emitir um julgamento de valor, independentemente do uso que será feito do seu produto.

Finalmente, o artigo de Tanaka reflete que a somatória dos esforços empreendidos pela comunidade de práticas brasileira da área de avaliação, aliada à sensibilidade dos atores tomadores de decisão no âmbito do SUS é a garantia de que estamos caminhando a passos largos para a construção de dispositivos concretos de institucionaliza- ção da avaliação de desempenho na área da saúde, a exemplos de países como Canadá ${ }^{32}$, Reino Unido $^{33}$ e França ${ }^{34}$.

\section{Referências}

1. Hartz ZMA Avaliação dos programas de Saúde: perspectivas teórico metodológicas e politicas institucionais. Cien Saude Colet 1999; 4(2):341-353.

2. Silva LMV, Formigli VLA. Avaliação em saúde: limites e perspectivas. Cad Saude Publica 1994; 10(1):80-91.

3. Tanaka OY, Melo C. Avaliação de programa de saúde do adolescente: um modo de fazer. São Paulo: Edusp; 2001.

4. Tanaka OY. Caminhos alternativos para a institucionalização da avaliação em saúde. Cien Saude Colet 2006; 11(3):571-572.

5. Felisberto E. Da teoria à formulação de uma Política Nacional de Avaliação em Saúde: reabrindo o debate. Cien Saude Colet 2006; 11(3):553-563.

6. Brousselle A, Champagne F, Contrandriopoulos AP, Hartz Z, organizadores. Avaliação: Conceitos e Métodos. Rio de Janeiro: Editora Fiocruz; 2011.

7. Dubois CA, Champagne F, Bilodeau H. História da avaliação. In: Brousselle A, Champagne F, Contrandriopoulos AP, Hartz Z, organizadores. Avaliação: Conceitos e Métodos. Rio de Janeiro: Editora Fiocruz; 2011.

8. Contandriopoulos AP. Avaliando a institucionalização da avaliação. Cien Saude Colet 2006; 11(3):705-711.

9. Denis JL. Institucionalização da avaliação na administração pública. Rev. Bras. Saude Mater. Infant. 2010; 10(Supl. 1):s229-s333.

10. Avaliação de Desempenho do Sistema de Saúde Brasileiro (PRO-ADESS): indicadores para monitoramento. Relatório final. [acessado $2012 \mathrm{fev} 21$ ]. Disponível em: http://www.proadess.cict.fiocruz.br/SGDP-RELATORIOFINAL30-7-2011.pdf

11. Avaliação de Desempenho do Sistema de Saúde Brasileiro (PRO-ADESS): Matriz dos indicadores do Proadess. Página na internet [acessado 2012 fev 21]. Disponível em: http://www.proadess.cict.fiocruz.br/ index.php?pag=matr

12. Viacava F, Almeida C, Caetano R, Fausto M, Macinko J, Martins M, Noronha JC, Novaes HMD, Oliveira ES, Porto SM, Silva LMV, Szwarcwald CL. Uma metodologia de avaliação do desempenho do sistema de saúde brasileiro. Cien Saude Colet 2004; 9(3):711-724.

13. Kickbusch I, Payne L. Meeting on global health governance and accountability. Constructing global public health in the 21st Century. 2-3 June 2004. Página na Internet. [acessado: 2008 ago 20]. Disponível em: http://www.ilonakickbusch.com/global-health-governance/index.shtml

14. Matus C. Política, planejamento \& governo. tomo I. $3^{\text {a }}$ ed. Brasília: Instituto de Pesquisa Econômica Aplicada (IPEA); 1997.

15. Martins CE. O circuito do poder: Democracia, participação, descentralização. São Paulo: Editora Entrelinhas; 1994.

16. Santos MHC. Governabilidade e governança: criação de capacidade governativa e o processo decisório no Brasil pós-constituinte. Anales del I Congreso Interamericano del CLAD sobre la Reforma del Estado y de la Administración Pública. Caracas: Centro Latinoamericano de Administración para el Desarrollo; 1997. p. 452-466. 
17. Huntington SP. Political Order in Changing Socities. New Haven: Yale Univerty Press; 1968.

18. Pasquino G. Governabilidade in dicionário de política. v.1. 12a ed. Brasília: Editora UnB; 1999.

19. Rosenau JN, Czempiel E, organizadores. Governança sem governo: ordem e transformação na política mundial. Brasilia, São Paulo: Editora da Universidade de Brasília, Imprensa Oficial do Estado; 2000.

20. Denis JL, Champagne F, Pomey MP. Towards a Framework for Analysis of Governance in Health Care Organisations and Systems. Recherche de Publications CCHSA. Montreal: Université de Montreal; 2008.

21. Santos L, Andrade LOM. Redes interfederativas de saúde: um desafio para o SUS nos seus vinte anos. Cien Saude Colet 2011; 16(3):1671-1680.

22. Smith R. The future of healthcare systems. BMJ 1997; 314:1495-1496.

23. Guba ES, Lincoln Y. S5. Fourth generation evaluation. Newbury Park: Sage, 1989.

24. Testa M. Pensar em saúde. Porto Alegre: Artes Médicas/Abrasco; 1992.

25. Andrade LOM, Santos L. Relações Interfederativas. Relatório de estagio pós-doutoral, Université de Montreal. Brasília: CAPES; 2010.

26. Oliveira M, Andrade OM, Hairon CG, Moura RC, Fernandes S, Bringel J, Gensel J, Martin H, Sicotte C, Denis J-L. A Context-Aware Framework for Health Care Governance Decision-Making Systems: A model based on the Brazilian Digital TV. Second IEEE Workshop on Interdisciplinary Research on E-health Services and Systems (IREHSS), Montreal, 2010.

27. Dey AK, Abowd GD, Salber D. A Conceptual Framework and a Toolkit for Supporting the Rapid Prototyping of Context-Aware Applications. Journal Human-Computer Interaction 2001; 16(2):97-166.

28. Dittrich KR, Gatziu S, Geppert A. The Active Database Management System Manifesto: A Rulebase of ADBMS Features. RIDS '95 Proceedings of the Second International Workshop on Rules in Database Systems. London: Springer-Verlag; 1995.

29. Antunes F. SISA - Uma aplicação sensível ao contexto para agravos de Dengue: uma prova de conceito do projeto Lariisa [tese]. Fortaleza: Universidade Estadual do Ceará; 2011.

30. Frota JBB. Proposta de solução de integração de provedores de contexto ao sistema LARIISA [tese]. Fortaleza: Universidade Estadual do Ceará; 2011.

31. Santos MSS. Diga Saúde. Uma proposta de Apoio ao Serviço Home Care baseado no GINGA [tese]. Fortaleza: Universidade Estadual do Ceará; 2011.

32. Centre of Excellence for Evaluation, Treasury Board of Canada Secretariat. Report on Effective Evaluation Practices. [site na Internet]. [acessado $2012 \mathrm{fev} 23$ ]. Disponível em: http://www.tbs-sct.gc.ca/cee/toolsoutils/eep-pee-eng.asp

33. United Kingdom Evaluation Society. [site na Internet]. [acessado 2012 fev 23]. Disponível em: http:// www.evaluation.org.uk/index.aspx

34. Societé Française de l'Évaluation. Charte de l'évaluation des politiques publiques et des programmes publiques. [site na Internet]. 2006 [acessado $2012 \mathrm{fev} 23$ ]. Disponível em: http://ns206907.ovh.net/ ville/wpcontent/uploads/2011/07/charte-sfe_2006.pdf 